\title{
Estimating the Generalized Exponential Distribution Parameters and the Acceleration Factor under Constant-Stress Partially Accelerated Life Testing with Type-II Censoring
}

\author{
A. A. Ismail \\ King Saud University, Riyadh, Saudi Arabia
}

УДК 539.4

\begin{abstract}
Оценка параметров обобщенного экспоненциального распределения и коэффициента ускорения в условиях частично ускоренного ресурсного испытания с постоянным напряжением при цензурировании типа II
\end{abstract}

\begin{abstract}
А. А. Исмаил
Университет им. короля Сауда, Эр-Рияд, Саудовская Аравия

Ускоренные и частично ускоренные ресурсные испытания часто проводятся для обеспечения надежности современной техники. Цель таких испытаний - за короткий срок и с меньшими затратами получить информацию о ресурсе изделий и материалов. Испьтания можно проводить при постоянных, ступенчатых, прогрессирующих и цииклических нагрузках, $а$ также при нагрузке случайным напряжением. Рассматривается задача оценки параметров обобщенного экспоненциильного распределения и коэффициента ускорения в условиях частично ускоренного ресурсного испытания с постоянным напряжением. С использованием среднеквадратической погрешности проведено численное исследование эффективности оценки методом максимального правдоподобия для разных размеров образцов и значений параметра. Для параметров модели построены приблизительные доверительные границь. Чтобы получить доверительные границы для параметров модели в случае образца маленького размера, использовали метод отношения правдоподобия. В качестве примера проведено исследование с помощью моделирования. Показано, что результаты моделирования согласуются с данными расчетов.
\end{abstract}

Ключевые слова: техника обеспечения надежности, частично ускоренные ресурсные испытания, постоянное напряжение, обобщенное экспоненциальное распределение, оценка по методу максимального правдоподобия, границы отношения правдоподобия, цензурирование типа II.

\section{Notation}

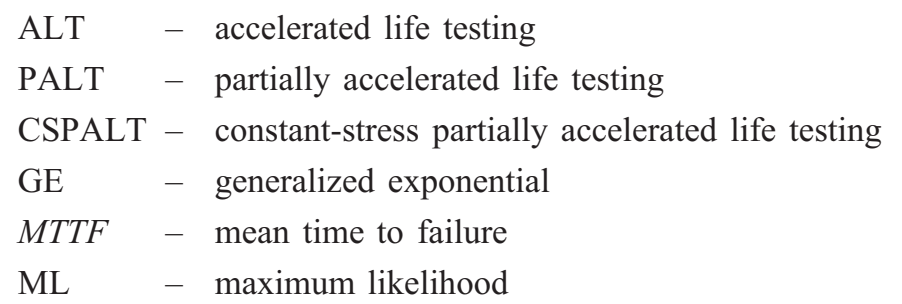




\begin{tabular}{|c|c|}
\hline$M L E S$ & - maximum likelihood estimates/estimators \\
\hline$L R$ & - likelihood ratio \\
\hline$L R B$ & - likelihood ratio bounds \\
\hline$M S E$ & - mean square error \\
\hline$C I$ & - confidence interval \\
\hline $1-\gamma$ & - confidence level \\
\hline$I W_{95}$ & - $C I$ width at $95 \%$ level of confidence \\
\hline$I W_{99}$ & - $C I$ width at $99 \%$ level of confidence \\
\hline$n$ & - total number of test items in a $P A L T$ (sample size) \\
\hline$y_{(r)}$ & - the time of the $r$ th failure at which the test is terminated \\
\hline$X$ & - lifetime of an item at normal (use) condition \\
\hline Y & - lifetime of an item at accelerated condition \\
\hline$(\hat{\imath})$ & - denotes maximum likelihood estimate \\
\hline$\beta$ & - acceleration factor $(\beta>1)$ \\
\hline$\alpha$ & - GE shape parameter $(\alpha>0)$ \\
\hline$\lambda$ & - GE scale parameter $(\lambda>0)$ \\
\hline$x_{i}$ & - observed lifetime of item $i$ tested at use condition \\
\hline$y_{j}$ & - observed lifetime of item $j$ tested at accelerated condition \\
\hline$\delta_{u i}, \delta_{a j}$ & $\begin{array}{l}-\quad \text { indicator functions: } \delta_{u i} \equiv I\left(X_{i} \leq y_{(r)}\right), \delta_{a j} \equiv I\left(Y_{j} \leq y_{(r)}\right) \\
\quad i=1, \ldots, n\end{array}$ \\
\hline$\pi$ & - proportion of sample units allocated to accelerated condition \\
\hline$n_{u}, n_{a}$ & $\begin{array}{l}\text { numbers of items failed at use and accelerated conditions, } \\
\text { respectively }\end{array}$ \\
\hline$r$ & - total number of failed units $\left(r=n_{u}+n_{a}\right)$ \\
\hline$L_{u i}\left(x_{i}, \delta_{u i}\right)$ & - the likelihood for $\left(x_{i}, \delta_{u i}\right), i=1, \ldots, n_{u}$ \\
\hline$L_{a j}\left(y_{j}, \delta_{a j}\right)$ & - the likelihood for $\left(y_{j}, \delta_{a j}\right), j=1, \ldots, n_{a}$ \\
\hline$x_{(1)} \leq \ldots \leq x_{\left(n_{u}\right)} \leq y_{(r)}$ & - ordered failure times at use condition \\
\hline$y_{(1)} \leq \ldots \leq y_{\left(n_{a}\right)} \leq y_{(r)}$ & - ordered failure times at accelerated condition \\
\hline
\end{tabular}

Introduction. Accelerated life testing (ALT) is frequently used in modern reliability engineering. By performing life tests at accelerated (i.e., harsher-thanuse) conditions, failures are quickly obtained, and products' reliability at normal (use) conditions can then be estimated via a stress-life relationship (dataextrapolation). In some cases such relationship is not known or can't be assumed and then the ALT methods can't be applied. Alternatively, another test method namely partially accelerated life testing (PALT) can be used to estimate and analyze products' reliability.

Such PALT results in shorter lives than would be observed under use condition. In PALT some of test units can be run under use condition and the others under accelerated condition. (In ALT, test units are run only at accelerated condition. Interested readers can refer to Nelson [1] and Meeker and Escobar [2] which are two comprehensible sources for ALT).

As Nelson [1] indicates, the stress can be applied in various ways, commonly used methods are step-stress and constant-stress. Under step-stress PALT, a test 
item is first run at use condition and, if it does not fail for a specified time, then it is run at accelerated condition until failure occurs or the observation is censored. But the constant-stress PALT runs each item at either use condition or accelerated condition only, i.e., each unit is run at a constant-stress level until the test is terminated. Accelerated test stresses involve higher than usual temperature, voltage, pressure, load, humidity, etc., or some combination of them. The objective of a PALT is then to collect more failure data in a limited time without necessarily using high stresses to all test units.

Compared with the step-stress accelerated life test (step-test), the constantstress accelerated life test (constant-test) has some merits as follows: simple test method, ripe theory, and precise test data. The constant-stress accelerated-life-test is commonly used to test the reliability of electric appliances. For an overview of constant-stress PALT (CSPALT), there are few studies in the literature in this respect: Bai and Chung [3] used the maximum likelihood method to estimate the scale parameter and the acceleration factor for exponentially distributed lifetimes under type-I censoring. Abdel-Ghani [4] considered the estimation problem for the Weibull distribution parameters. Ismail [5] used the maximum likelihood approach for estimating the acceleration factor and the parameters of Pareto distribution of the second kind. Ismail [6] extended the work of Abdel-Ghani [4] to study the problem of optimal design of the life test with type-II censored data. Recently, Ismail et al. [7] developed optimum constant-stress life test plans for Pareto distribution under type-I censoring.

The objective of this paper is to consider the CSPALT with type-II censoring for estimating the acceleration factor and the generalized exponential distribution parameters. A new distribution named as generalized exponential (GE) distribution or exponentiated exponential distribution was introduced by Gupta and Kundu [8] and since then it received a considerable attention in the literature. Several properties of the GE distribution were studied quite extensively; see for example, Gupta and Kundu [8-11]. The readers may be referred to some of the related literature on GE distribution by Raqab [12], Raqab and Ahsanullah [13] and Zheng [14]. The simple mathematical structure of the GE distribution enables it to be used effectively for modeling various lifetime data types with possible censoring or grouping Baklizi [15].

The two-parameter GE family has the distribution function

$$
F(x ; \alpha, \lambda)=\left(1-e^{-\lambda x}\right)^{\alpha}, \quad y>0 .
$$

The corresponding density function is

$$
f_{X}(x ; \alpha, \lambda)=\alpha \lambda\left(1-e^{-\lambda x}\right)^{\alpha-1} e^{-\lambda x}, \quad x>0, \quad \alpha>0, \quad \lambda>0,
$$

where $\alpha$ and $\lambda$ are the shape and scale parameters, respectively. When $\alpha=1$ it coincides with the exponential distribution with mean $1 / \lambda$. When $\alpha \leq 1$ the density function is strictly decreasing and for $\alpha>1$ it has a unimodal shape. These densities are illustrated in Gupta and Kundu [9]. It is clear that the GE density functions are always right skewed and it is observed that GE distributions can be used quite effectively to analyze skewed data sets. 
The hazard rate function of the GE distribution is

$$
h(x ; \alpha, \lambda)=\frac{\alpha \lambda e^{-\lambda x}\left(1-e^{-\lambda x}\right)^{\alpha-1}}{1-\left(1-e^{-\lambda x}\right)^{\alpha}},
$$

and the MTTF is

$$
\operatorname{MTTF}=\sum_{i=1}^{\infty}\left(\begin{array}{c}
\alpha \\
i
\end{array}\right) \frac{(-1)^{i+1}}{i \lambda} .
$$

The GE distribution can have increasing and decreasing hazard rates depending on the shape parameter $\alpha$. The hazard rate increases from 0 to $\lambda$ if $\alpha>1$ and if $\alpha<1$ it decreases from $\infty$ to $\lambda$. This property leads to a good ability of using this distribution in reliability and life testing, Abuammoh and Sarhan [16].

The reminder of the paper is organized as follows: in Section 1 the test procedure and its assumptions used throughout this paper are presented. In Section 2 two different methods are used to obtain the estimations of the unknown parameters. The first method is the maximum likelihood (ML) method when the sample size is large and the second one is the likelihood ratio bounds (LRB) method when the sample size is small. In Section 3 simulation studies are carried out to illustrate the theoretical results.

1. Test Procedure and Its Assumption. The test procedure of the CSPALT and its assumptions are described as follows:

Test Procedure. In a CSPALT, the total sample size $n$ of test units is divided into two parts such that:

1. $n \pi$ units randomly chosen among $n$ test units sampled are allocated to accelerated condition and the remaining are allocated to use condition.

2. Each test unit is run until it fails or the test is terminated.

Assumptions.

1. The lifetimes $X_{i}, i=1, \ldots, n(1-\pi)$ of units allocated to use condition, are i.i.d. r.v.'s.

2. The lifetimes $Y_{j}, j=1, \ldots, n \pi$ of units allocated to accelerated condition, are i.i.d r.v.'s.

3. The lifetimes $X_{i}$ and $Y_{j}$ are mutually statistically-independent.

4. The lifetimes of the test units follow the GE distribution.

2. Parameter Estimation.

2.1. ML Estimation. In a simple constant-stress PALT, the test item is run either at use condition or at accelerated condition only. Since the lifetimes of the test items follow the GE distribution, the probability density function (pdf) of an item tested at use condition is given as in (2). While for an item tested at accelerated condition, the pdf is given by

$$
\begin{gathered}
f_{Y}(y ; \beta, \alpha, \lambda)=\beta \alpha \lambda\left(1-e^{-\beta \lambda y}\right)^{\alpha-1} e^{-\beta \lambda y}, \\
y>0, \quad \beta>1, \quad \alpha>0, \quad \lambda>0,
\end{gathered}
$$

where $Y=\beta^{-1} X$. 
Since the test in type-II censoring is terminated at a predetermined $r$ of failures, the observed lifetimes $x_{(1)} \leq \ldots \leq x_{\left(n_{u}\right)} \leq y_{(r)}$ and $y_{(1)} \leq \ldots \leq y_{\left(n_{a}\right)} \leq y_{(r)}$ are ordered failure times at use and accelerated conditions respectively, where $n_{u}$ and $n_{a}$ are the numbers of items failed at use and accelerated conditions, respectively.

Let the indicator functions: $\delta_{u i} \equiv I\left(X_{i} \leq y_{(r)}\right)$ and $\delta_{a j} \equiv I\left(Y_{j} \leq y_{(r)}\right)$. Then the total likelihood for $\left(x_{1} ; \delta_{u 1}, \ldots, x_{n(1-\pi)} ; \delta_{u n(1-\pi)}, y_{1} ; \delta_{a 1}, \ldots, y_{n \pi} ; \delta_{a n \pi}\right)$ is given by

$$
\begin{aligned}
& L(\underline{x}, \underline{y} \mid \beta, \alpha, \lambda) \propto \prod_{i=1}^{n \bar{\pi}} L_{u i}\left(x_{i}, \delta_{u i} \mid \alpha, \lambda\right) \prod_{j=1}^{n \pi} L_{a j}\left(y_{j}, \delta_{a j} \mid \beta, \alpha, \lambda\right)= \\
& \quad=\prod_{i=1}^{n \bar{\pi}}\left\{\alpha \lambda\left(1-e^{-\lambda_{x_{i}}}\right)^{\alpha-1} e^{-\lambda_{x_{i}}}\right\}^{\delta_{u_{i}}}\left\{1-\left(1-e^{-\lambda y_{(r)}}\right)^{\alpha}\right\}^{\bar{\delta}_{u_{i}}} \times \\
& \times \prod_{j=1}^{n \pi}\left\{\beta \alpha \lambda\left(1-e^{-\beta \lambda_{y_{j}}}\right)^{\alpha-1} e^{-\beta \lambda_{y_{j}}}\right\}^{\delta_{a_{j}}}\left\{1-\left(1-e^{-\beta \lambda_{y_{(r)}}}\right)^{\alpha}\right\}^{\bar{\delta}_{a_{j}}},
\end{aligned}
$$

where

$$
\bar{\delta}_{u i}=1-\delta_{u i}, \quad \bar{\delta}_{a j}=1-\delta_{a j}, \quad \text { and } \quad \bar{\pi}=1-\pi
$$

We can write the total likelihood function by another possibility, in terms of the order statistics indicated earlier, as

$$
\begin{aligned}
& L(\underline{x}, \underline{y} \mid \beta, \alpha, \lambda) \propto \prod_{i=1}^{n_{u}}\left\{\alpha \lambda\left(1-e^{-\lambda_{x_{i}}}\right)^{\alpha-1} e^{-\lambda_{x_{i}}}\right\} \prod_{i=n_{u}+1}^{n \bar{\pi}}\left\{1-\left(1-e^{-\lambda y_{(r)}}\right)^{\alpha}\right\} \times \\
& \quad \times \prod_{j=1}^{n_{a}}\left\{\beta \alpha \lambda\left(1-e^{-\beta \lambda_{y_{j}}}\right)^{\alpha-1} e^{-\beta \lambda_{y_{j}}}\right\} \prod_{j=n_{a}+1}^{n \pi}\left\{1-\left(1-e^{-\beta \lambda y_{(r)}}\right)^{\alpha}\right\} .
\end{aligned}
$$

The $\log$-likelihood function, $\ln L$, is

$$
\begin{gathered}
\ln L=n_{u} \ln \alpha+n_{u} \ln \lambda+(\alpha-1) \sum_{i=1}^{n \bar{\pi}} \ln \left(1-e^{-\lambda_{x_{i}}}\right)-\lambda \sum_{j=1}^{n \bar{\pi}} x_{i}+ \\
+n_{u} \ln \left[1-\left(1-e^{-\lambda y_{(r)}}\right)^{\alpha}\right]+n_{a} \ln \beta+n_{a} \ln \alpha+n_{a} \ln (\lambda)+ \\
+(\alpha-1) \sum_{j=1}^{n \pi} \ln \left(1-e^{-\beta \lambda_{y_{j}}}\right)-\beta \lambda \sum_{j=1}^{n \pi} y_{j}+n_{a} \ln \left[1-\left(1-e^{-\beta \lambda y_{(r)}}\right)^{\alpha}\right] .
\end{gathered}
$$


The normal equations become

$$
\begin{aligned}
& \frac{\partial \ln L}{\partial \beta}=\frac{n_{a}}{\beta}+(\alpha-1) \lambda \sum_{i=1}^{n_{a}} \frac{y_{j} e^{-\beta \lambda_{y_{j}}}}{1-e^{-\beta \lambda_{y_{j}}}}-\lambda \sum_{j=1}^{n_{u}} y_{j}- \\
& -\frac{\alpha \lambda y_{(r)} n_{a} e^{-\beta \lambda y_{(r)}}\left(1-e^{-\beta \lambda y_{(r)}}\right)^{\alpha-1}}{1-\left(1-e^{-\beta \lambda y_{(r)}}\right)^{\alpha}}=0 \\
& \frac{\partial \ln L}{\partial \alpha}=\frac{n_{u}+n_{a}}{\alpha}+\sum_{i=1}^{n_{u}} \ln \left(1-e^{-\lambda_{x_{i}}}\right)+\sum_{j=1}^{n_{a}} \ln \left(1-e^{-\beta \lambda_{y_{j}}}\right)- \\
& -\frac{n_{u}\left(1-e^{-\lambda y_{(r)}}\right)^{\alpha} \ln \left(1-e^{-\lambda y_{(r)}}\right)}{1-\left(1-e^{-\lambda y_{(r)}}\right)^{\alpha}}-\frac{n_{a}\left(1-e^{-\beta \lambda y_{(r)}}\right)^{\alpha} \ln \left(1-e^{-\beta \lambda y_{(r)}}\right)}{1-\left(1-e^{-\beta \lambda y_{(r)}}\right)^{\alpha}}=0, \\
& \frac{\partial \ln L}{\partial \lambda}=\frac{n_{u}+n_{a}}{\lambda}+(\alpha-1) \sum_{i=1}^{n_{u}} \frac{x_{i} e^{-\lambda_{x_{i}}}}{\left(1-e^{-\lambda_{x_{i}}}\right)}- \\
& -\sum_{j=1}^{n_{u}} x_{i}-\frac{n_{u} \alpha y_{(r)}\left(1-e^{-\lambda y_{(r)}}\right)^{\alpha-1} e^{-\lambda y_{(r)}}}{1-\left(1-e^{-\lambda y_{(r)}}\right)^{\alpha}}+(\alpha-1) \beta \sum_{i=1}^{n_{a}} \frac{y_{j} e^{-\beta \lambda_{y_{j}}}}{\left(1-e^{-\beta \lambda_{y_{j}}}\right)}- \\
& -\beta \sum_{j=1}^{n_{a}} y_{j}-\frac{n_{a} \alpha \beta y_{(r)}\left(1-e^{-\beta \lambda y_{(r)}}\right)^{\alpha-1} e^{-\beta \lambda y_{(r)}}}{1-\left(1-e^{-\beta \lambda y_{(r)}}\right)^{\alpha}}=0 .
\end{aligned}
$$

Now, we have a system of three nonlinear equations in three unknowns $\beta, \alpha$, and $\lambda$. It is clear that a closed form solution is very difficult to obtain. Therefore, iterative procedure can be used to find a numerical solution of the above system.

Concerning the asymptotic confidence intervals of the model parameters, it is not possible to derive the exact distributions of the $M L E$ of the parameters because the likelihood equations have no closed form solutions in the unknown parameters $\beta, \alpha$, and $\lambda$. Thus, approximate confidence intervals of the parameters are derived based on the asymptotic distributions of the $M L E$ of the elements of the vector of unknown parameters $\theta=(\beta, \alpha, \lambda)$. It is known that the asymptotic distribution of the $M L E$ of $\theta$ is given by (see Miller [17])

$$
((\hat{\beta}-\beta),(\hat{\alpha}-\alpha),(\hat{\lambda}-\lambda)) \rightarrow N\left(0, I^{-1}(\beta, \alpha, \lambda)\right),
$$

where $I^{-1}(\beta, \alpha, \lambda)$ is the variance-covariance matrix of the unknown parameters $\theta=(\beta, \alpha, \lambda)$. The elements of the $3 \times 3$ matrix $I, I_{i j}(\beta, \alpha, \lambda), i, j=1,2,3$; can be approximated by $I_{i j}(\hat{\beta}, \hat{\alpha}, \hat{\lambda})$, where 


$$
I_{i j}(\hat{\theta})=-\left.\frac{\partial^{2} \ln L(\theta)}{\partial \theta_{i} \partial \theta_{j}}\right|_{\theta=\hat{\theta}}
$$

From Eq. (7), we get the following:

$$
\begin{aligned}
& \frac{\partial^{2} \ln L}{\partial \beta^{2}}=-\frac{n_{a}}{\beta^{2}}-(\alpha-1) \lambda^{2} \sum_{j=1}^{n_{a}} \frac{y_{j}^{2} e^{-\beta \lambda_{y_{j}}} \psi_{3 j}+y_{j}^{2} e^{-2 \beta \lambda_{y_{j}}}}{\psi_{3 j}^{2}}- \\
& -\frac{\alpha \lambda^{2} y_{(r)}^{2} e^{-\beta \lambda y_{(r)}} n_{a}\left\{\left[(\alpha-1) \psi_{5} e^{-\beta \lambda y_{(r)}}-\psi_{5}^{2}\right]\left[1-\psi_{5}^{\alpha}\right]+\alpha \psi_{5}^{2(\alpha-1)} e^{-\beta \lambda y_{(r)}}\right\}}{\psi_{5}^{2}}, \\
& \frac{\partial^{2} \ln L}{\partial \alpha^{2}}=-\frac{n_{u}}{\alpha^{2}}-\frac{n_{u} \psi_{2}^{\alpha}\left(\ln \psi_{2}\right)^{2}\left\{\left(1-\psi_{2}^{\alpha}\right)+\psi_{2}^{\alpha}\right\}}{\left(1-\psi_{2}^{\alpha}\right)^{2}}-\frac{n_{a}}{\alpha^{2}}- \\
& -\frac{n_{a}\left(\ln \psi_{6}\right)^{2}\left\{\psi_{5} \psi_{6}^{\alpha}+\left(1-\psi_{5}\right)^{2}\right\}}{\psi_{5}^{2}} \\
& \frac{\partial^{2} \ln L}{\partial \lambda^{2}}=-\frac{n_{u}+n_{a}}{\lambda^{2}}-(\alpha-1) \sum_{i=1}^{n_{u}} \frac{x_{i}^{2} e^{-\lambda_{x_{i}}}\left(\psi_{1 i}+e^{-\lambda_{x_{i}}}\right)}{\psi_{1 i}^{2}}- \\
& -\frac{n_{u} \alpha y_{(r)}^{2}\left\{\left[(\alpha-1) \psi_{2}^{\alpha-2} e^{-\lambda y_{(r)}}-\psi_{2}^{\alpha-1} e^{-\lambda y_{(r)}}\right]\left[1-\psi_{2}^{\alpha}\right]+\alpha \psi_{2}^{2(\alpha-1)} e^{-2 \lambda y_{(r)}}\right\}}{\psi_{5}^{2}}+ \\
& +(\alpha-1) \beta^{2} \sum_{j=1}^{n_{a}} \frac{y_{j}^{2} e^{-\beta \lambda_{y_{j}}}\left(\psi_{3 j}-e^{-\beta \lambda_{y_{j}}}\right)}{\psi_{3 j}^{2}}- \\
& -\frac{n_{a} \alpha \beta^{2} y_{(r)}^{2}\left\{\psi_{5} e^{-\beta \lambda y_{(r)}}\left[(\alpha-1) \psi_{6}^{\alpha-2}-\psi_{6}^{\alpha-1}\right]+\alpha \psi_{6}^{2(\alpha-1)} e^{-2 \beta \lambda y_{(r)}}\right\}}{\psi_{5}^{2}}, \\
& \frac{\partial^{2} \ln L}{\partial \beta \partial \alpha}=\lambda \sum_{j=1}^{n_{a}} \frac{y_{j} e^{-\beta \lambda_{y_{j}}}}{\psi_{3 j}}- \\
& -\frac{n_{a} \lambda y_{(r)} e^{-\beta \lambda y_{(r)}}\left\{\left[\psi_{6}^{\alpha-2}+\alpha \psi_{6}^{\alpha-1} \ln \psi_{6}\right] \psi_{5}+\alpha \psi_{6}^{2(\alpha-1)} \ln \psi_{6}\right\}}{\psi_{5}^{2}},
\end{aligned}
$$$$
\frac{\partial^{2} \ln L}{\partial \beta \partial \lambda}=(\alpha-1)\left\{\sum_{j=1}^{n_{a}} \frac{y_{j} e^{-\beta \lambda_{y_{j}}}}{\psi_{3 j}}-\lambda \beta \sum_{j=1}^{n_{a}} \frac{y_{j}^{2} e^{-\beta \lambda_{y_{j}}}\left(\psi_{3 j}+e^{-\beta \lambda_{y_{j}}}\right)}{\psi_{3 j}^{2}}\right\}-\sum_{j=1}^{n_{a}} y_{j}-
$$ 


$$
\begin{aligned}
& -\frac{n_{a} \alpha y_{(r)} e^{-\beta \lambda y_{(r)}}}{\psi_{5}^{2}}\left\{\left[1-\lambda \beta y_{(r)} \psi_{6}^{\alpha-1}+(\alpha-1) \lambda \beta y_{(r)} e^{-\beta \lambda y_{(r)}} \psi_{6}^{\alpha-2}\right] \psi_{5}+\right. \\
& \left.+\alpha \lambda e^{-\beta \lambda y_{(r)}} \psi_{6}^{2(\alpha-1)}\right\} \\
& \frac{\partial^{2} \ln L}{\partial \alpha \partial \lambda}=\sum_{i=1}^{n_{u}} \frac{x_{i} e^{-\lambda_{x_{i}}}}{\psi_{1 i}}+\beta \sum_{j=1}^{n_{a}} \frac{y_{j} e^{-\beta \lambda_{y_{j}}}}{\psi_{3 j}}- \\
& -\frac{n_{u}}{\psi_{4}^{2}}\left\{\left[\alpha y_{(r)} \psi_{2}^{\alpha-1} e^{-\lambda y_{(r)}}-\ln \psi_{2}\right]+y_{(r)} \psi_{2}^{\alpha-1} e^{-\lambda y_{(r)}}\right] \psi_{4}+ \\
& \left.+\alpha y_{(r)} \psi_{2}^{2 \alpha-1} \ln \psi_{2} e^{-\lambda y_{(r)}}\right\}-\frac{n_{a}}{\psi_{5}^{2}}\left\{\left[\alpha y_{(r)} \beta \psi_{6}^{\alpha-1} e^{-\beta \lambda y_{(r)}} \ln \psi_{6}+\right.\right. \\
& \left.\left.+y_{(r)} \beta \psi_{6}^{\alpha-1} e^{-\beta \lambda y_{(r)}}\right] \psi_{5}+\alpha y_{(r)} \beta \psi_{6}^{2 \alpha-1} \ln \psi_{6} e^{-\beta \lambda y_{(r)}}\right\},
\end{aligned}
$$

where

$$
\begin{gathered}
\psi_{1 i}=1-e^{-\lambda_{x_{i}}}, \quad \psi_{2}=1-e^{-\lambda y_{(r)}}, \quad \psi_{3 j}=1-e^{-\beta \lambda_{y_{j}}} \\
\psi_{4}=1-\left(1-e^{-\lambda y_{(r)}}\right)^{\alpha}, \quad \psi_{5}=1-\left(1-e^{-\beta \lambda y_{(r)}}\right)^{\alpha}, \quad \psi_{6}=1-e^{-\beta \lambda y_{(r)}} .
\end{gathered}
$$

Thus, the approximate $100(1-\gamma) \%$ two sided confidence intervals for $\beta, \alpha$, and $\lambda$ are, respectively, given by

$$
\hat{\beta} \pm Z_{\gamma / 2} \sqrt{I_{11}^{-1}(\hat{\beta})}, \quad \hat{\alpha} \pm Z_{\gamma / 2} \sqrt{I_{22}^{-1}(\hat{\alpha})}, \quad \hat{\lambda} \pm Z_{\gamma / 2} \sqrt{I_{33}^{-1}(\hat{\lambda})}
$$

where $Z_{\gamma / 2}$ is the upper $100(\gamma / 2)$ th percentile of a standard normal distribution.

2.2. LRB Estimation. The ML estimates are based on large sample normal theory. However, when there are only few failures, the large sample normal theory is not very accurate. Thus, the ML estimates could be very different from the true values. The LRB method is based on the $\chi$-squared distribution assumption. For example, Vander Wiel and Meeker [18] investigated the accuracy of the likelihood ratio (LR)-based confidence bounds and asymptotic s-normal-based confidence bounds using censored Wiebull regression data from constant-stress ALT. It is noted that the $L R$ bounds perform better than the ML-based bounds when the sample size is small. In this subsection we will use the LRB method to obtain the confidence bounds of the model parameters when the sample size is small.

Here, we will apply the LRB method to derive the confidence bounds for a vector of unknown parameters $\theta(\beta, \alpha, \lambda)$ when the sample size is small. We treat the $L R$ as a function on $\theta$ defined by

$$
L R(\theta)=\frac{L(\beta, \alpha, \lambda)}{L(\hat{\beta}, \hat{\alpha}, \hat{\lambda})},
$$


where $L(\beta, \alpha, \lambda)$ is the likelihood function with three parameters $\beta, \alpha$, and $\lambda$, and $\hat{\beta}$, $\hat{\alpha}$, and $\hat{\lambda}$ are their estimated values.

Because the $\log$ likelihood ratio statistic is $X^{2}$ distributed, that is, $-2 \log L R(\theta) \approx X_{\gamma, k}^{2}$, with $k$ degrees of freedom (the number of quantities jointly estimated), then, the confidence bounds over which $L R(\theta)>e^{X_{\gamma, k}^{2} / 2}$ is the $100(1-\gamma) \% L R B$ for $\theta$.

There is no closed-form solution available. Therefore, it is very difficult (there are more than two parameters) to discuss $L R$ bounds except for simulation study which has been done by others (e.g., McSorley et al. [19]). The simulation results of the $L R$ bounds of our model parameters are presented in Tables 1 and 2. For the $L R$ bounds of the model parameters when the sample size is small, the simulation results are calculated based on the $\chi$-squared distribution and are reported in these tables. These results support the theoretical findings.

$\mathrm{T}$ a b 1 e 1

Simulation Results of the $\boldsymbol{L R}$ Bounds of the Model Parameters Using Small Samples $(\beta=1.3, \alpha=0.5$, and $\lambda=0.7)$

\begin{tabular}{||c|c|c|c|c|c||}
\hline$n$ & Parameter & $\begin{array}{c}\text { Lower bound } \\
95 \%\end{array}$ & $\begin{array}{c}\text { Upper bound } \\
95 \%\end{array}$ & $\begin{array}{c}\text { Lower bound } \\
99 \%\end{array}$ & $\begin{array}{c}\text { Upper bound } \\
9 \%\end{array}$ \\
\hline \multirow{2}{*}{10} & $\beta$ & 0.88330 & 2.363765 & 0.794970 & 2.659236 \\
& $\alpha$ & 0.33932 & 0.673620 & 0.305388 & 0.757823 \\
& $\lambda$ & 0.36953 & 0.948625 & 0.332577 & 1.067203 \\
\hline \multirow{2}{*}{15} & $\beta$ & 0.81750 & 2.199545 & 0.735750 & 2.474488 \\
& $\alpha$ & 0.37065 & 0.650370 & 0.333585 & 0.731666 \\
& $\lambda$ & 0.24325 & 0.743185 & 0.218925 & 0.836083 \\
\hline \multirow{2}{*}{20} & $\beta$ & 0.93918 & 1.870935 & 0.845262 & 2.104802 \\
& $\alpha$ & 0.42480 & 0.632850 & 0.382320 & 0.711956 \\
& $\lambda$ & 0.42942 & 0.813705 & 0.386478 & 0.915418 \\
\hline \multirow{2}{*}{25} & $\alpha$ & 0.99072 & 1.641350 & 0.891648 & 1.846519 \\
& $\alpha$ & 0.45559 & 0.623440 & 0.410031 & 0.701370 \\
& $\lambda$ & 0.48816 & 0.802060 & 0.439344 & 0.902318 \\
\hline
\end{tabular}

3. Simulation Studies. In this section, a simulation study is conducted to illustrate the theoretical results given in this paper and to investigate the performance of the $M L E s$ of the model parameters via their mean square error (MSE). Moreover, the performance of the various approximate intervals presented in this paper is studied. The simulation algorithm or procedure can be described as follows.

Step 1. 10,000 random samples of sizes 30, 50, 75, and 100 are generated from the GE distribution. Two sets of the true parameter values $\beta, \alpha$, and $\lambda$ are considered to be $1.3,0.5,0.7$ and $2.2,1.4,1.1$, respectively.

Step 2. Considering the allocation parameter $\pi$ to be $\pi=0.5$.

Step 3. For the two sets of parameters and for each sample size, the two parameters of the GE distribution and the acceleration factor are estimated under CSPALT with type-II censored data using the maximum likelihood approach. 
T a b 1 e 2

Simulation Results of the $\boldsymbol{L R}$ Bounds of the Model Parameters Using Small Samples $(\beta=2.2, \alpha=1.4$, and $\lambda=1.1)$

\begin{tabular}{||c|c|c|c|c|c||}
\hline$n$ & Parameter & $\begin{array}{c}\text { Lower bound } \\
95 \%\end{array}$ & $\begin{array}{c}\text { Upper bound } \\
95 \%\end{array}$ & $\begin{array}{c}\text { Lower bound } \\
99 \%\end{array}$ & $\begin{array}{c}\text { Upper bound } \\
99 \%\end{array}$ \\
\hline \multirow{2}{*}{10} & $\beta$ & 1.44683 & 5.771750 & 1.229806 & 6.060338 \\
& $\alpha$ & 0.70889 & 2.826875 & 0.602557 & 2.968219 \\
& $\lambda$ & 0.16919 & 1.813125 & 0.143812 & 1.903781 \\
\hline \multirow{2}{*}{15} & $\beta$ & 1.51844 & 4.416750 & 1.290674 & 4.637588 \\
& $\alpha$ & 0.75075 & 2.357875 & 0.638138 & 2.475769 \\
& $\lambda$ & 0.35182 & 1.674500 & 0.299047 & 1.758225 \\
\hline \multirow{2}{*}{20} & $\beta$ & 1.67937 & 3.528875 & 1.127465 & 3.705319 \\
& $\alpha$ & 0.92281 & 1.810375 & 0.784389 & 1.900894 \\
& $\lambda$ & 0.71729 & 1.558125 & 0.609697 & 1.636031 \\
\hline \multirow{2}{*}{25} & $\alpha$ & 1.72627 & 3.322625 & 1.267330 & 3.488756 \\
& $\alpha$ & 0.86569 & 1.615125 & 0.735837 & 1.695881 \\
& $\lambda$ & 0.84035 & 1.549625 & 0.714298 & 1.627106 \\
\hline
\end{tabular}

T a b 1 e 3

Average Values of the MLEs, MSE, Variance, $I W_{95}$, and $I W_{99}$ $(\beta=1.3, \alpha=0.5$, and $\lambda=0.7)$

\begin{tabular}{||c|c|c|c|c|c|c||}
\hline$n$ & Parameter & $M L E$ & $M S E$ & Variance & $I W_{95}$ & $I W_{99}$ \\
\hline \multirow{2}{*}{30} & $\beta$ & 1.193727 & 0.326016 & 0.132593 & 1.427402 & 1.878927 \\
& $\alpha$ & 0.757161 & 0.231624 & 0.004154 & 0.252650 & 0.332570 \\
& $\lambda$ & 0.528947 & 0.104616 & 0.010251 & 0.396889 & 0.522436 \\
\hline \multirow{2}{*}{50} & $\beta$ & 1.233921 & 0.175032 & 0.132593 & 1.266506 & 1.667135 \\
& $\alpha$ & 0.664767 & 0.141264 & 0.004154 & 0.210406 & 0.276963 \\
& $\lambda$ & 0.590717 & 0.070704 & 0.010251 & 0.276019 & 0.363331 \\
\hline \multirow{2}{*}{75} & $\beta$ & 1.272472 & 0.114624 & 0.008442 & 0.360171 & 0.474103 \\
& $\alpha$ & 0.568719 & 0.081504 & 0.001742 & 0.163610 & 0.215364 \\
& $\lambda$ & 0.664158 & 0.035064 & 0.002948 & 0.212838 & 0.280165 \\
\hline \multirow{2}{*}{100} & $\beta$ & 1.318393 & 0.053496 & 0.001005 & 0.124271 & 0.163581 \\
& $\alpha$ & 0.501048 & 0.030888 & 0.000670 & 0.101467 & 0.133563 \\
& $\lambda$ & 0.682955 & 0.062024 & 0.000871 & 0.115690 & 0.152286 \\
\hline
\end{tabular}

Step 4. The Newton-Raphson method is used to solve the nonlinear likelihood equations for $\beta, \alpha$, and $\lambda$ numerically.

Step 5. The MSE of the MLES of model parameters is computed for different sized samples and different sets of parameter values.

Step 6. The asymptotic variances of the estimators of model parameters are estimated for different sized samples and different sets of parameter values.

Step 7. The approximate confidence bounds with confidence level $\gamma=0.95$ and 0.99 are obtained for the three parameters of the model.

By conducting the above steps using a computer program written in the Pascal language, the simulation results are reported in Tables 3 and 4. As shown from the 
$\mathrm{T}$ a $\mathrm{b} 1$ e 4

Average Values of the MLEs, MSE, Variance, $I W_{\mathbf{9 5}}$, and $I W_{\mathbf{9 9}}$

$(\beta=2.2, \alpha=1.4$, and $\lambda=1.1)$

\begin{tabular}{|c|c|c|c|c|c|c||}
\hline$n$ & Parameter & $M L E$ & $M S E$ & Variance & $I W_{95}$ & $I W_{99}$ \\
\hline \multirow{2}{*}{30} & $\beta$ & 3.412658 & 0.304116 & 0.106191 & 1.277409 & 1.681487 \\
& $\alpha$ & 0.919338 & 0.103726 & 0.089262 & 1.171168 & 1.541640 \\
& $\lambda$ & 0.797132 & 0.171306 & 0.033372 & 0.716106 & 0.942629 \\
\hline \multirow{2}{*}{50} & $\beta$ & 2.905014 & 0.178002 & 0.061803 & 0.974520 & 1.282787 \\
& $\alpha$ & 1.083096 & 0.044950 & 0.048843 & 0.866338 & 1.140383 \\
& $\lambda$ & 0.985296 & 0.082088 & 0.009639 & 0.384859 & 0.506601 \\
\hline \multirow{2}{*}{75} & $\beta$ & 2.303450 & 0.113274 & 0.021789 & 0.578635 & 0.761673 \\
& $\alpha$ & 1.321138 & 0.015686 & 0.026487 & 0.637973 & 0.839781 \\
& $\lambda$ & 1.035468 & 0.037882 & 0.002835 & 0.208719 & 0.274743 \\
\hline \multirow{2}{*}{100} & $\beta$ & 2.225172 & 0.067518 & 0.001134 & 0.132006 & 0.173763 \\
& $\alpha$ & 1.394834 & 0.001744 & 0.000972 & 0.122214 & 0.160873 \\
& $\lambda$ & 1.067906 & 0.009688 & 0.001458 & 0.149680 & 0.197028 \\
\hline \hline
\end{tabular}

numerical results, the maximum likelihood estimators have good statistical properties. The estimates of the parameters approach the true values as the sample size increases. Also, the estimated asymptotic variances of the estimators decrease as the sample size increases. Moreover, the estimated approximate confidence intervals for the three parameters are to be narrower when the sample size is getting to be larger.

Conclusions. In this paper the problem of estimating the generalized exponential distribution parameters and the acceleration factor in the case of constant-stress partially accelerated life tests was considered under type-II censoring. The maximum likelihood method was used to estimate the model parameters using the Newton-Raphson method. The performance of the estimators was investigated numerically for different parameter values and different sample sizes. Moreover, the approximate confidence bounds of the model parameters were obtained at 95 and $99 \%$ levels of confidence.

It is concluded that the numerical results support the theoretical findings. That is, the maximum likelihood estimators are consistent and their asymptotic variances decrease as the sample size increases. Moreover, the estimated approximate confidence intervals for the three parameters are to be smaller when the sample size is getting to be larger. In addition, the confidence intervals obtained at confidence level $\gamma=0.95$ are narrower than those at $\gamma=0.99$. Another method, namely, the LRB method was used to obtain the confidence bounds of the model parameters when the sample size is small. The simulation results of this method support the theoretical findings. That is, good estimations were obtained using this method when the sample size is small. As a future work, this study can be extended to deal with the problem of estimation using progressively type-II censored data assuming the same distribution under CSPALT.

Acknowledgements. This project was supported by King Saud University, Deanship of Scientific Research, College of Science Research Center. 
Прискорені та частково прискорені ресурсні випробування часто проводяться для забезпечення надійності сучасної техніки. Метою таких випробувань є за короткий проміжок часу та з найменшими затратами отримати інформацію про ресурс виробів і матеріалів. Випробування можна проводити за постійних, східчастих, прогресуючих і циклічних навантажень, а також при навантаженні випадковим напруженням. Розглядається задача оцінки параметрів загального експоненціального розподілу та коефіцієнта прискорення в умовах частково прискореного ресурсного випробування з постійною напругою. Із використанням середньоквадратичної похибки проведено чисельне дослідження ефективності оцінки методом максимальної правдоподібності для різних розмірів зразка та значень параметра. Для параметрів моделі побудовано приблизні довірчі границі. Щоб отримати довірчі границі для параметра моделі у випадку зразка маленького розміру, використовували метод відношення правдоподібності. Як приклад проведено дослідження за допомогою моделювання. Показано, що результати моделювання збігаються 3 даними розрахунків.

1. W. Nelson, Accelerated Testing: Statistical Models, Data Analysis and Test Plans, John Wiley and Sons, New York (1990).

2. W. Q. Meeker and L. A. Escobar, Statistical Methods for Reliability Data, Wiley, New York (1998).

3. D. S. Bai and S. W. Chung, "Optimal design of partially accelerated life tests for the exponential distribution under type-I censoring," IEEE Trans. Reliab., 41, 400-406 (1992).

4. M. M. Abdel-Ghani, Investigation of some Lifetime Models under Partially Accelerated Life Tests, Ph.D. Thesis, Department of Statistics, Faculty of Economics and Political Science, Cairo University, Egypt (1998).

5. A. A. Ismail, The Test Design and Parameter Estimation of Pareto Lifetime Distribution under Partially Accelerated Life Tests, Ph.D. Thesis, Department of Statistics, Faculty of Economics \& Political Science, Cairo University, Egypt (2004).

6. A. A. Ismail, "Planning constant-stress partially accelerated life tests with type-II censoring," J. Statist. Theory Appl., 7, 407-418 (2008).

7. A. A. Ismail, A. A. Abdel-Ghaly, and E. H. El-Khodary, "Optimum constantstress life test plans for Pareto distribution under type-I censoring," J. Statist. Comput. Simul., 81, 1835-1845 (2011).

8. R. D. Gupta and D. Kundu, "Generalized exponential distributions," Austral. New Zealand J. Statist., 41, 173-188 (1999).

9. R. D. Gupta and D. Kundu, "Generalized exponential distribution: an alternative to gamma and Weibull distributions," Biometr. J., 43, 117-130 (2001).

10. R. D. Gupta and D. Kundu, "Generalized exponential distribution: different methods of estimation," J. Statist. Comput. Simul., 69, 315-338 (2001). 
11. R. D. Gupta and D. Kundu, "Generalized exponential distributions: statistical inferences," J. Statist. Theory Appl., 1, 101-118 (2002).

12. M. Z. Raqab, "Inferences for Generalized exponential distribution based on record statistics," J. Statist. Plan. Infer., 104, 339-350 (2002).

13. M. Z. Raqab and M. Ashanullah, "Estimation of the location and scale parameters of generalized exponential distribution based on order statistics," J. Statist. Comput. Simul., 69, 109-123 (2001).

14. G. Zheng, "On the Fisher information matrix in type-II censored data from exponentiated exponential family," Biometr. J., 44, 353-357 (2002).

15. A. Baklizi, "Likelihood and Bayesian estimation of $\operatorname{Pr}(\mathrm{X}<\mathrm{Y})$ using lower record values from the generalized exponential distribution," Comput. Statist. Data Anal., 52, 3468-3473 (2007).

16. A. Abuammoh and A. M. Sarhan, "Parameters estimators for the generalized exponential distribution," Int. J. Reliab. Appl., 8, 17-25 (2007).

17. R. G. Miller, Survival Analysis, John Wiley, New York (1981).

18. S. A. Van der Wiel and W. Q. Meeker, "Accuracy of approximate confidence bounds using censored Weibull regression data from accelerated life tests," IEEE Trans. Reliab., 39, No. 3, 346-351 (1990).

19. E. O. McSorley, J. C. Lu, and C. S. Li, "Performance of parameter estimates in step-stress accelerated life tests with various sample sizes," IEEE Trans. Reliab., 51, 271-277 (2002). 